\title{
Availability of iron from chicken meat and liver given to rats
}

\author{
BY FUNKE E. BOGUNJOKO, R. J. NEALE* AND D. A. LEDWARD \\ Department of Applied Biochemistry and Food Science, University of Nottingham School \\ of Agriculture, Sutton Bonington, Loughborough, Leics. LE12 5RD
}

(Received 18 February 1983 - Accepted 6 June 1983)

1. The concentration and distribution of iron in ${ }^{59} \mathrm{Fe}-$ labelled chicken leg and breast meat and liver were determined by gel filtration. In all samples approximately $50 \%$ of the Fe was insoluble (haemosiderin) and the haemoproteins (haemoglobin and myoglobin) constituted from $15 \%$ (liver) to $25 \%$ (leg meat) of the total Fe. Ferritin accounted for from $12 \%$ (leg meat) to $27 \%$ (liver) of the total Fe.

2. A technique was developed which enabled the time-course of the passage of ${ }^{59} \mathrm{Fe}-$ labelled whole and fractionated meat and liver through the gastrointestinal tract of Fe-replete and Fe-deficient rats to be followed and it was found that the rate of stomach emptying appeared to be a function of the viscosity of the meal. In Fe-replete rats approximately $71 \%$ of a meal of raw chicken meat had left the stomach within $1 \mathrm{~h}$ of administration and by $2 \mathrm{~h}$ the stomach was almost empty and much of the unabsorbed ${ }^{50} \mathrm{Fe}$ was in the ileum. By $4 \mathrm{~h}$ the ileum and colon contained almost equal amounts of ${ }^{59} \mathrm{Fe}$. Between different test meals there were only slight differences in gastrointestinal distribution and these reflected the different rates of stomach emptying.

3. Stomach emptying was slower in Fe-deficient compared with Fe-replete rats.

4. In Fe-replete, but not Fe-deficient, rats it was found that the amount of ${ }^{59} \mathrm{Fe}$ lost (absorbed) from the gastrointestinal tract $2 \mathrm{~h}$ after administration of a test meal was not significantly different from the value found using a $7 \mathrm{~d}$ faecal collection technique.

5. Comparison of the $2 \mathrm{~h}$ absorption values for several test meals indicated that ${ }^{59} \mathrm{Fe}$ absorption from raw whole meat was significantly higher than from the soluble extract and the residue after extraction (haemosiderin).

6. Heat treatment caused a significant decrease in the absorption of $F e$ in whole meat and the soluble meat extract but a significant increase in the liver absorption values. It is suggested that denatured haemoproteins are less available for absorption than their native forms but that heating increases the availability of the $\mathrm{Fe}$ of haemosiderin or ferritin or both.

7. Isolated muscle ferritin was poorly absorbed but on the addition of excess bovine serum albumin the absorption of the Fe was markedly increased.

8. It is concluded that, to estimate the Fe availability of a food such as chicken meat or liver one must not only take account of the concentration and type of each Fe-containing compound present but also such factors as their possible synergistic effects, the presence of chelating agents, the extent of cooking and the concentration and type of proteinaceous digestion products.

It is well established that iron absorption from meat is greater than that from plant foods and in a mixed diet a high proportion of total dietary $\mathrm{Fe}$ absorbed is from meat (Bjorn-Rasmussen et al. 1974). The high availability of $\mathrm{Fe}$ from meat is suggested as being due to the presence of haem-Fe which is a major form of $\mathrm{Fe}$ in some meats and which is well absorbed across the intestinal mucosa (Conrad et al. 1967). Recently it has been suggested that although intact haem may well be absorbed from haemoglobin, the previously-described mechanism may not be appropriate for haemoproteins in a meat environment (Hazell et al. 1978, 1980). In meat systems it was suggested that the digestion of haemoproteins led primarily to the formation of readily absorbed low-molecular-weight non-haem-Fe complexes. The level of haem-Fe in meat varies widely and recent work by Hazell (1982) has shown variations in haem-Fe from approximately $25 \%$ of the total $\mathrm{Fe}$ in white meat (chicken) to $60 \%$ of the total $\mathrm{Fe}$ in red meat (beef). The remaining non-haem-Fe which comprises ferritin, low-molecular-weight $\mathrm{Fe}$ compounds and insoluble haemosiderin also varies considerably between meats. These variations in $\mathrm{Fe}$ content and composition might well be expected to alter the availability of the total $\mathrm{Fe}$ from a variety of meat samples. In the present study we have characterized the Fe compounds in chicken meat and liver and determined the availability of $\mathrm{Fe}$ associated with them using rats as experimental animals. 


\section{MATERIALS AND METHODS}

\section{Preparation of labelled feeding material}

The Fe-containing compounds of chicken muscle and liver were labelled with ${ }^{59} \mathrm{Fe}$ by intraperitoneal injection of about $1 \mathrm{ml}$ of a solution containing approximately $200 \mu \mathrm{Ci}$ $\left[{ }^{58} \mathrm{Fe}\right]$ ferric citrate $(14 \mu \mathrm{g} \mathrm{Fe} / \mathrm{ml}$; Amersham International, Amersham, Bucks) into 4weeks-old chicks. The chicks were kept in individual cages and fed on broiler rations for a further 4 weeks before slaughter. Four weeks was an arbitrary time period chosen in order to achieve uniform labelling of all $\mathrm{Fe}$ pools. Evidence that this occurred is shown in the agreement found between chemical and radioactive Fe determinations (Table 1, see p. 514). Chickens were slaughtered by cervical dislocation and bleeding and ${ }^{59} \mathrm{Fe}-$ labelled meat obtained separately from breast (pectoral), leg and hip muscles and liver. Meat was stored at $-20^{\circ}$ until required.

\section{Chemical and radioactive analysis}

${ }^{59} \mathrm{Fe}$ concentrations were determined by gamma-counting weighed amounts of tissue in a well-type sodium iodide crystal gamma-counter (Nuclear Enterprises Model ST3). Total Fe contents were measured by atomic absorption spectrophotometry (EEL 240). For solid samples the $\mathrm{Fe}$ was solubilized by wet ashing using sulphuric acid and hydrogen peroxide. Spectral scans from 250 to $290 \mathrm{~nm}$ and from 390 to $430 \mathrm{~nm}$ were used to estimate protein (peak approximately $280 \mathrm{~nm}$ ) and haemoprotein (peak approximately $410 \mathrm{~nm}$ ) concentrations of solutions.

\section{Distribution of radioactive Fe in chicken muscle and liver}

Samples (50 g wet weight) of muscle and liver were cut up into small pieces $\left(1 \mathrm{~mm}^{3}\right)$ and shaken at 160 oscillations/min with a MKV shaker in $250 \mathrm{ml} \mathrm{0.1} \mathrm{M-potassium} \mathrm{orthophos-}$ phate buffer, $\mathrm{pH} 6.0$, for $3 \mathrm{~h}$. Alternatively, samples were homogenized (MSE homogenizer) with buffer for $1 \mathrm{~min}$. The slurry was centrifuged at $4000 \mathrm{~g}$ at $0^{\circ}$ for $1 \mathrm{~h}$ and the residue then reshaken or homogenized with buffer and recentrifuged. The pooled supernatant fractions were concentrated by rotary vacuum evaporation before subsequent analysis. Analysis of supernatant fractions and residues for ${ }^{59} \mathrm{Fe}$ gave the percentage soluble $\mathrm{Fe}$ in the sample. Soluble Fe compounds in the supernatant fraction were subsequently fractionated on Sephadex G 200 (column height $340 \mathrm{~mm}$, bed volume $210 \mathrm{ml}$, flow rate $5 \mathrm{ml} / \mathrm{h}$; Pharmacia Fine Chemicals, Uppsala, Sweden) or Sephacryl S-300 (height $420 \mathrm{~mm}$, bed volume $350 \mathrm{ml}$, flow-rate $20 \mathrm{ml} / \mathrm{h}$; Sigma Chemical Co., Poole, Dorset). The columns were equilibrated and eluted with $0.1 \mathrm{M}$-potassium orthophosphate buffer, $\mathrm{pH} 6.0$. Fractions ( 3 or $5 \mathrm{ml}$ ) were collected and analysed for ${ }^{59} \mathrm{Fe}$, protein and haemoprotein. The column was calibrated with ferritin, bovine serum albumin, myoglobin, cytochrome $c$, aprotinin and glucagon.

\section{In vivo absorption of ${ }^{59} \mathrm{Fe}$}

Fe-replete male and female Wistar rats, weighing $150-200 \mathrm{~g}$, were used in the study. Occasionally Fe-deficient rats were used which were rendered anaemic by giving weanling rats a casein-based low-Fe diet for 4 weeks. Blood haemoglobin levels were measured to determine quantitatively the extent of the anaemia (Boehringer Test Kit, Boehringer, London). All food was removed overnight from test animals and the following morning $5 \mathrm{ml}$ portions of a test meal (described on p. 513) were given intragastrically by oral intubation. Rats were killed by a sharp blow to the head and cervical dislocation at 5,30 , 60,120 and $240 \mathrm{~min}$ after dosing. The abdominal cavity was opened and ligatures placed at the gastro-oesophageal junction, pylorus, ileocaecal junction and rectum. The intestine 
was then removed carefully and further ligatures tied $100 \mathrm{~mm}$ from the pylorus (duodenum), $600 \mathrm{~mm}$ from the dudodenum (jejunum) and the remainder of the gut was then considered to be the ileum. The contents of each segment of gastrointestinal tract were obtained by careful washing with cold saline $(9 \mathrm{~g}$ sodium chloride/1). The remaining segments were retained for counting. ${ }^{59} \mathrm{Fe}$ activity was measured in test dose, luminal contents and segment walls and ${ }^{59} \mathrm{Fe}$ absorption calculated as the difference between the ${ }^{59} \mathrm{Fe}$ administered and ${ }^{59} \mathrm{Fe}$ recovered in luminal contents and gut walls. In some $7-\mathrm{d}$ absorption studies, ${ }^{59} \mathrm{Fe}$ absorption was estimated by measuring the ${ }^{59} \mathrm{Fe}$ activity excreted in faeces and urine from rats dosed by intragastric intubation (as described previously). Following the test meal rats were kept in stainless-steel metabolism cages with food and water available ad lib. and faeces were collected until less than $1 \%$ of the administered dose of ${ }^{59} \mathrm{Fe}$ was excreted in $24 \mathrm{~h} .{ }^{59} \mathrm{Fe}$ absorption in the $7 \mathrm{~d}$ study was measured and all unrecovered ${ }^{59} \mathrm{Fe}$ in faeces and urine was assumed to have been absorbed and retained.

\section{Composition of test meals}

Ten test meals each containing $6.7 \mu \mathrm{g} \mathrm{Fe} / \mathrm{ml}$ were prepared from the pre-labelled chicken tissues as follows: (1) raw whole chicken leg meat was prepared by homogenizing a known weight in a measured volume of distilled water; (2) cooked whole chicken meat was obtained by heating a known weight of chicken leg meat in distilled water at $90^{\circ}$ for $30 \mathrm{~min}$ and then homogenizing; (3) raw chicken meat extract (containing water-soluble Fe-containing compounds) was obtained by homogenizing a known weight of chicken leg meat in distilled water and centrifuging the slurry at $4000 \mathrm{~g}$ for $30 \mathrm{~min}$; (4) cooked chicken meat extract was prepared by heating the soluble extract obtained as for test meal (3) to $90^{\circ}$ for $30 \mathrm{~min}$ and rehomogenizing; (5) raw chicken insoluble residue (haemosiderin) was obtained as for test meal (3) and a known weight calculated to give $6.7 \mu \mathrm{g} \mathrm{Fe} / \mathrm{ml}$ was resuspended in distilled water and rehomogenized; (6) cooked chicken insoluble residue was obtained by cooking the weighed water-extracted residue, prepared as in test meal (5), in distilled water for $30 \mathrm{~min}$ at $90^{\circ}$ followed by homogenization; (7) chicken haemoproteins from leg meat were obtained by homogenizing a known weight of leg meat in distilled water, centrifuging the slurry at $4000 \mathrm{~g}$ and then heating the resulting supernatant fraction at $90^{\circ}$ for $30 \mathrm{~min}$ to precipitate the haemoproteins. On cooling, the heat coagulum was separated from the supernatant fraction and the resulting heat coagulum (haemoproteins) rehomogenized in distilled water to give an $\mathrm{Fe}$ concentration of $6.7 \mu \mathrm{g} / \mathrm{ml}$; (8) muscle ferritin was assumed to be present in the supernatant fraction after the heat precipitation of the haemoproteins from the soluble muscle extract. The low-molecular-weight $\mathrm{Fe}$ compounds were removed from this solution by dialysis against ten times its volume of deionized water with continuous stirring for $72 \mathrm{~h}$ at $1^{\circ}$, water being changed every $24 \mathrm{~h}$; the retentate was regarded as ferritin; ( 9 and 10) raw and cooked chicken liver test meals were obtained as for the test meals (1) and (2). However, because of the very high liver-Fe levels much smaller samples of liver were needed to give the same Fe concentration.

\section{RESULTS}

\section{Characteristics of Fe-labelled chicken muscle and liver}

Total Fe contents. The mean (with SE) relative specific activities of the breast, rump-hip, leg and liver samples were 3100 (79), $6600(200), 8100$ (250) and 94900 (3000) counts/min per $\mathrm{g}$ dry weight respectively for triplicate determinations of radioactivity of two samples. Thus the relative $\mathrm{Fe}$ contents of the four samples were $1: 2 \cdot 1: 2 \cdot 6: 30 \cdot 6$. Chemical analysis on breast, leg and liver samples from six chickens grown under identical conditions to those used in the radioactive study gave mean (with SE) total $\mathrm{Fe}$ contents $(\mathrm{mg} / \mathrm{kg}$ wet weight) of 
Table 1. Distribution (\% total iron content) of Fe-containing compounds in chicken breast, leg and liver

(Values are means with their standard errors for six determinations)

\begin{tabular}{|c|c|c|c|c|c|c|c|c|c|c|c|c|}
\hline & \multicolumn{4}{|c|}{ Breast } & \multicolumn{4}{|c|}{ Leg } & \multicolumn{4}{|c|}{ Liver } \\
\hline & \multicolumn{2}{|c|}{ C } & \multicolumn{2}{|c|}{$\mathbf{R}$} & \multicolumn{2}{|c|}{ C } & \multicolumn{2}{|c|}{$\mathbf{R}$} & \multicolumn{2}{|c|}{ C } & \multicolumn{2}{|c|}{$\mathbf{R}$} \\
\hline & Mean & $\mathrm{SE}$ & Mean & $\mathbf{S E}$ & Mean & $\mathrm{sE}$ & Mean & $\mathrm{SE}$ & Mean & $\mathrm{SE}$ & Mean & SE \\
\hline $\begin{array}{l}\text { Insoluble } \mathrm{Fe} \\
\text { (haemosiderin) }\end{array}$ & $57 \cdot 2$ & 1.9 & $56 \cdot 0$ & 0.7 & $43 \cdot 1$ & 1.2 & $57 \cdot 3$ & $1 \cdot 2$ & $49 \cdot 6$ & 0.8 & 53.6 & 1.2 \\
\hline Ferritin & $14 \cdot 7$ & 0.4 & $20 \cdot 4$ & 1.8 & $12 \cdot 6$ & 0.7 & $11 \cdot 2$ & 1.9 & $24 \cdot 6$ & 0.5 & $29 \cdot 4$ & $2 \cdot 6$ \\
\hline Haemoglobin & $10 \cdot 7$ & $1 \cdot 2$ & $9 \cdot 3$ & $0 \cdot 8$ & $7 \cdot 8$ & 0.3 & $8 \cdot 1$ & 0.7 & $11 \cdot 5$ & 0.9 & 7.6 & 0.02 \\
\hline Myoglobin & $6 \cdot 6$ & $0 \cdot 1$ & $7 \cdot 8$ & $0 \cdot 3$ & $20 \cdot 4$ & 0.3 & 15.5 & $2 \cdot 3$ & $5 \cdot 5$ & $0 \cdot 1$ & $5 \cdot 3$ & 0.2 \\
\hline $\begin{array}{l}\text { Low-molecular-weight } \\
\text { compounds }\end{array}$ & $10 \cdot 1$ & 0.8 & $3 \cdot 5$ & $0 \cdot 1$ & $13 \cdot 1$ & 1.2 & 5.9 & 0.6 & $8 \cdot 5$ & 0.7 & $3 \cdot 1$ & 0.1 \\
\hline
\end{tabular}

C, determined by atomic absorption spectrophotometry; $R$, obtained from relative ${ }^{59} \mathrm{Fe}$ activities.

$5 \cdot 3(0 \cdot 3), 18 \cdot 3(2 \cdot 6)$ and $201 \cdot 5(13 \cdot 0)$ respectively, which are in general agreement with the relative values found by determination of the specific activities of the labelled samples.

\section{Distribution of Fe compounds}

In all cases approximately $50 \%$ of the total $\mathrm{Fe}$, whether measured chemically or by ${ }^{59} \mathrm{Fe}$ activity, was extracted into the phosphate buffer. The elution profile of the extracts of all samples analysed gave four ${ }^{59} \mathrm{Fe}$ positive peaks and the relative positions of these were the same as obtained by chemical analysis for a range of meats by Hazell (1982). The first peak to elute on the columns corresponded to the elution volume of the column (molecular weight 600000 for Sephadex G-200) and, as shown by Hazell (1982) consisted primarily of ferritin. The two intermediate peaks eluted at the same positions as pure haemoglobin and myoglobin and, as they absorbed strongly in the Soret region and the concentrated extracts had typical haemoprotein spectra they undoubtedly corresponded to these compounds. The lowest molecular weight ${ }^{59} \mathrm{Fe}$ positive peak had no haemoprotein character as judged by absorption spectrophotometry and possibly was composed of low-molecular-weight amino acid complexes.

The relative distribution of the five Fe compounds, determined by ${ }^{59} \mathrm{Fe}$ activity, is shown in Table 1. In addition, the fractions comprising each peak on the chromatogram were collected, concentrated and the total Fe contents found by atomic absorption spectrophotometry. The results are also shown in Table 1. It can be seen that the agreement between the different methods was good although the chemical analysis appeared to yield slightly higher concentrations for the low-molecular-weight compounds than those determined by the ${ }^{50} \mathrm{Fe}$ concentration.

The relative distribution of the Fe compounds shown in Table 1 reflected the variability between the different samples. While $50 \%$ of the total $\mathrm{Fe}$ was insoluble (haemosiderin), haem-Fe accounted for from $15 \%$ (liver) to $25 \%$ (leg) of total $\mathrm{Fe}$, whereas ferritin accounted for from $12 \%$ (leg) to $27 \%$ (liver) of the total $\mathrm{Fe}$.

\section{In vivo studies}

Flow-rates of test meals through the gastrointestinal tract. Gastric emptying of test meals in Fe-replete rats was in most cases rapid: $71,65,90,62$ and $44 \%$ of test meals 1, 2, 3, 

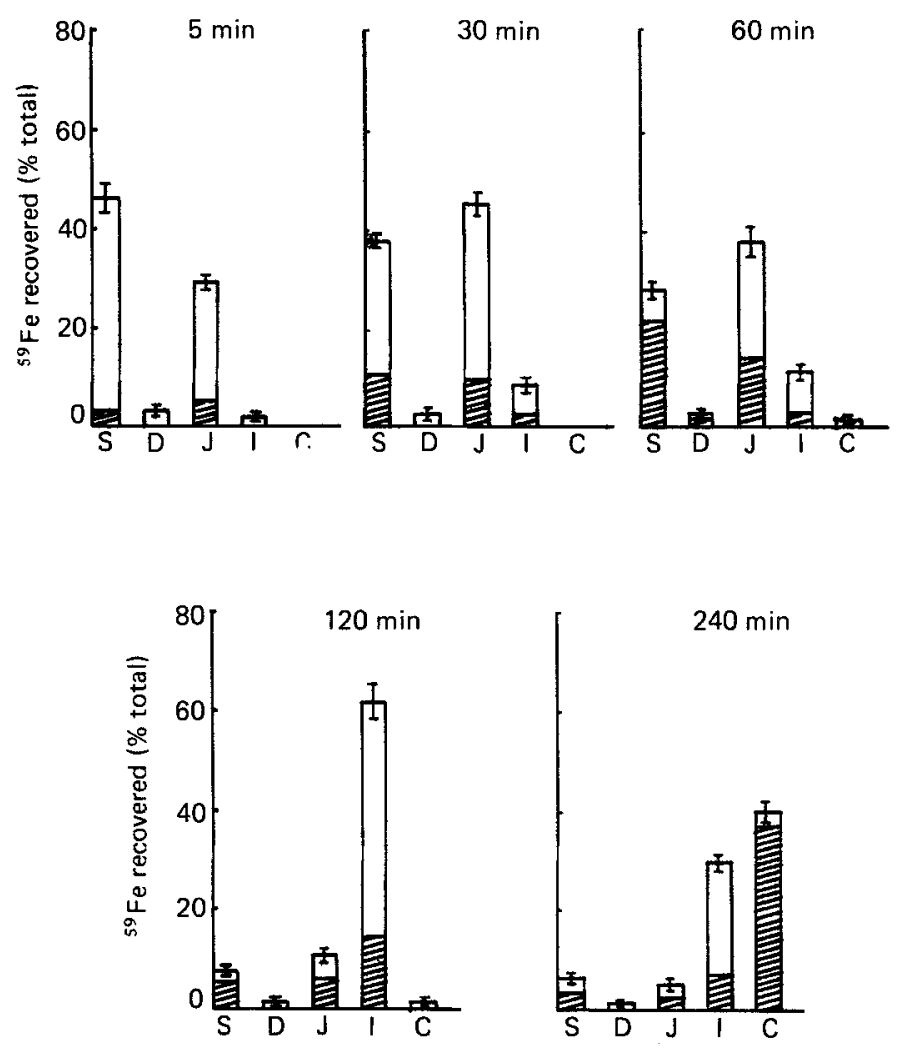

Fig. 1. Percentage distribution of unabsorbed ${ }^{59} \mathrm{Fe}$ in the lumen $(\square)$ and gut wall (एZय) of various regions of rat gastrointestinal tract at various time-intevals after intragastric injection of raw chicken meat test meal. Values are means with their standard errors represented by vertical bars for four or eight rats per group. S, stomach; K, duodenum; J, jejunum; I, ileum; C, large intestine and colon.

4 and 6 left the stomach after $60 \mathrm{~min}$ and $94,72,100,75$ and $70 \%$ of test meals $1,2,3$, 4 and 6 left the stomach after $4 \mathrm{~h}$. The difference between meals was no doubt affected by viscosity as subjective assessment indicated that the cooked insoluble residue (test meal (6)) had the highest viscosity and the raw extract (test meal (3)) the lowest.

Fig. 1 shows the typical distribution of unabsorbed Fe in the gastrointestinal tract of Fe-replete rats at various time-intervals after giving the raw chicken meat meal (test meal (1)). There was an early phase of rapid stomach emptying ( $5 \mathrm{~min}$ ) when approximately $30 \%$ ${ }^{59} \mathrm{Fe}$ was present in the jejunum and with increasing time stomach ${ }^{59} \mathrm{Fe}$ levels fell more slowly with jejunal and ileal levels rising. After $120 \mathrm{~min}$ the stomach was almost empty and much of the unabsorbed ${ }^{59} \mathrm{Fe}$ was in the ileum. After $240 \mathrm{~min}$ the ileum and colon contained almost equal amounts of ${ }^{59} \mathrm{Fe}$. Between test meals there were only slight differences in the gastrointestinal distribution with time and these essentially reflected the different rates of stomach emptying. In most cases a large proportion of ${ }^{59} \mathrm{Fe}$ given had left the stomach within $120 \mathrm{~min}$ and much of the unabsorbed ${ }^{59} \mathrm{Fe}$ was in the ileum. This finding corresponds in general with the peak in ${ }^{59} \mathrm{Fe}$ absorption which occurred at about 120 min after dosing (see p. 516). There was evidence for slower stomach emptying in Fe-deficient rats as compared with Fe-replete rats given whole raw chicken meat. Thus at 120 min, 18 (SE 4)\% of the ${ }^{59} \mathrm{Fe}$ given was still in the stomach of the Fe-deficient rats compared with 


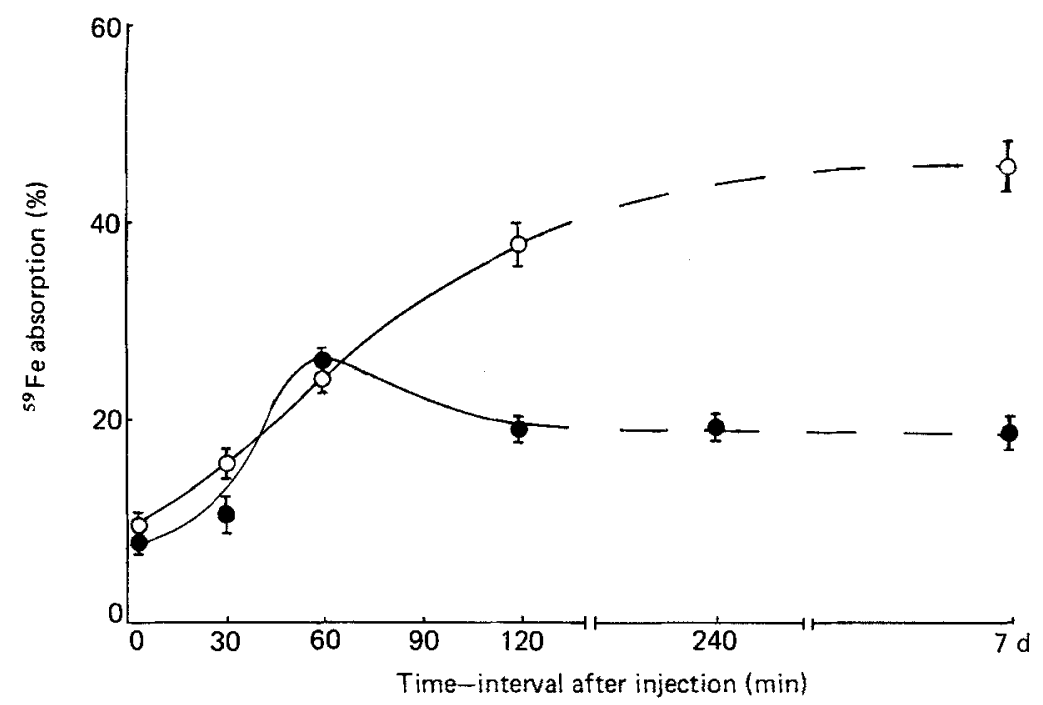

Fig. 2. Percentage absorption of ${ }^{50} \mathrm{Fe}$ from raw chicken leg meat in iron-replete $(\mathrm{O}-\mathrm{O})$ and Fe-deficient $(\mathrm{O}-\mathrm{O})$ rats over various time-intervals after intragastric injection of test meal. Points are mean values with their standard errors represented by vertical bars for four or eight rats per group.

7 (SE 2)\% in the Fe-replete rats. This may be an important adaptive mechanism for Fedeficient rats to slow Fe release to the small intestine and thereby increase its contact time with the intestinal mucosa.

\section{Absorption of ${ }^{59} \mathrm{Fe}$ from test meals}

Fig. 2 shows the percentage absorption of ${ }^{59} \mathrm{Fe}$ over various time-intervals from whole chicken meat meal (test meal (1)) in Fe-replete and Fe-deficient rats whose average initial haemoglobin concentrations were 148 and $97 \mathrm{~g} / 1$ blood respectively. ${ }^{59} \mathrm{Fe}$ absorption increased rapidly over the first 60 min reaching a maximum value for Fe-replete rats $(26 \cdot 1 \%)$ but then appearing to fall off at 120 and $240 \mathrm{~min}$ (18.3 and $19.6 \%$ respectively). In Fe-deficient rats ${ }^{59} \mathrm{Fe}$ absorption continued to increase after $60 \mathrm{~min}$ reaching $36.2 \%$ at $120 \mathrm{~min}$. No results were obtained at $240 \mathrm{~min}$.

The mean (with SE) ${ }^{50} \mathrm{Fe}$ absorption using the $7 \mathrm{~d}$ faecal collection technique in Fe-replete rats $(n 8)$ was $18.7(1) \%$ and for Fe-deficient rats $(n 8)$ was $47.0(2) \%$. Other results using cooked whole chicken and raw and cooked chicken extract in Fe-replete rats showed that the 120 min absorption period gave ${ }^{59} \mathrm{Fe}$ absorption values similar to those at $7 \mathrm{~d}$ (Fig. 3). It was therefore decided to use the $120 \mathrm{~min}$ time-interval for all other ${ }^{59} \mathrm{Fe}$ absorption tests. Since Fe-deficient rats showed no such agreement in ${ }^{50} \mathrm{Fe}$ absorption between $120 \mathrm{~min}$ and $7 \mathrm{~d}$ a $120 \mathrm{~min}$ time period would not be appropriate for studies involving these rats. No further studies were done with Fe-deficient rats.

${ }^{50} \mathrm{Fe}$ absorption from all other forms of chicken meat and liver in Fe-replete rats after 120 min are shown in Table $2 .{ }^{59} \mathrm{Fe}$ absorption from raw whole meat was significantly higher than that from meat extract $(P<0.05)$ and from extraction residue (haemosiderin) $(P<0.001)$.

Absorption of Fe from raw chicken liver was lower than that from muscle, but not significantly so $(P>0.05)$. 


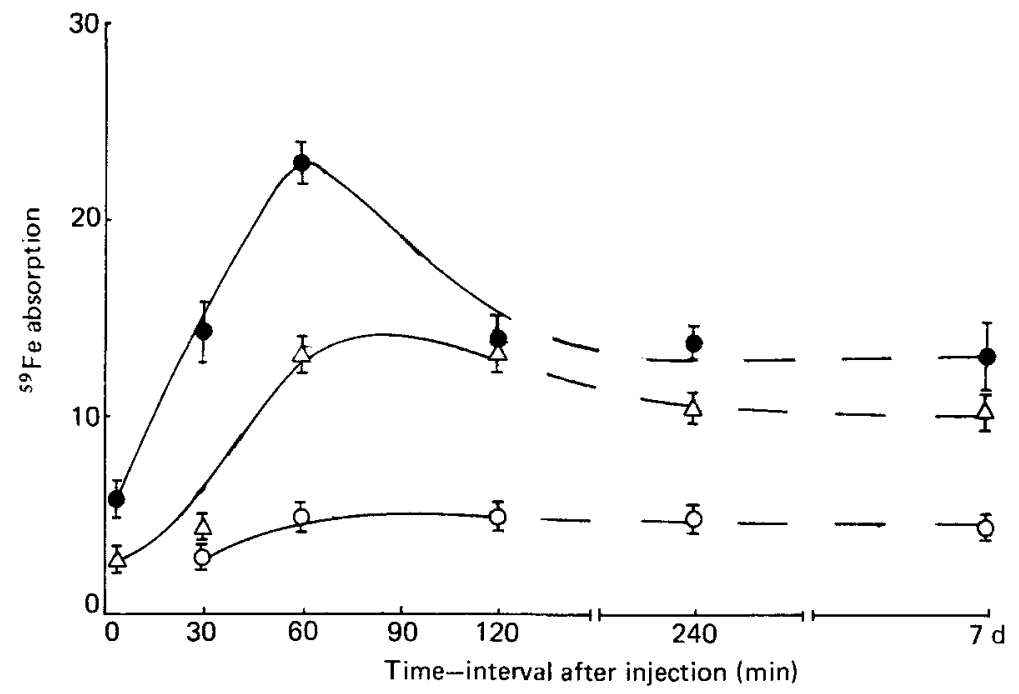

Fig. 3. Percentage absorption of ${ }^{59} \mathrm{Fe}$ from cooked chicken meat $(\triangle-\triangle)$ and raw $(\mathrm{O}-\mathrm{O})$ and cooked $(\mathrm{O}-\mathrm{O})$ extract in Fe-replete rats over various time-intervals after intragastric injection of test meals. Points are mean values with their standard errors represented by vertical bars for four or eight rats per group.

Table 2. Percentage absorption of ${ }^{59} \mathrm{Fe}$ at 120 min after ingestion of various types of chicken meat and liver under different treatments using Fe-replete rats

(Values are means with their standard errors; no. of rats in parentheses)

\begin{tabular}{|c|c|c|c|}
\hline \multicolumn{2}{|r|}{ Test meal* } & \multicolumn{2}{|c|}{${ }^{5 \theta} \mathrm{Fe}$ absorption $(\%)$} \\
\hline No. & Type $†$ & Mean & SE \\
\hline 1 & Raw whole leg meat & $18 \cdot 3$ & $1.5(8)$ \\
\hline 3 & Raw leg meat extract & $13 \cdot 4$ & $1 \cdot 1(8)$ \\
\hline 5 & Raw leg meat extraction residue & $6 \cdot 7$ & $0.6(4)$ \\
\hline 9 & Raw liver & $15 \cdot 3$ & $1.8(4)$ \\
\hline 2 & Cooked whole leg meat & $12 \cdot 7$ & $0.4(4)$ \\
\hline 4 & Cooked leg meat extract & $4 \cdot 3$ & $0.7(4)$ \\
\hline 6 & Cooked leg meat extraction residue & $7 \cdot 6$ & $1 \cdot 1(4)$ \\
\hline 10 & Cooked liver & $21 \cdot 3$ & $1 \cdot 1(4)$ \\
\hline 7 & Haemoprotein (cooked leg) & $4 \cdot 6$ & $0.4(4)$ \\
\hline 8 & Muscle ferritin (cooked leg) & $2 \cdot 5$ & $0 \cdot 1(4)$ \\
\hline
\end{tabular}

* For details of preparation, see p. 513 .

$\dagger 5 \mathrm{ml}$ containing $6.7 \mu \mathrm{g} \mathrm{Fe} / \mathrm{ml}$.

\section{Effects of cooking on ${ }^{59} \mathrm{Fe}$ absorption from chicken meat and liver}

These results are also summarized in Table 2 and it was found that cooking significantly reduced Fe absorption in whole chicken meat from 18.3 to $12.7 \%(P<0.05)$. The decrease obtained on heating the meat extract was even higher, i.e. $13.4 \%$ compared with $4.3 \%$. Cooking the extraction residue, however, slightly increased $\mathrm{Fe}$ absorption from 6.7 to $7.6 \%$, but the difference was not significant $(P>0.05)$. Rats given cooked liver, however, absorbed significantly more $\mathrm{Fe}(21.3 \%)$ than those given raw liver $(15.3 \%, P<0.025)$. Absorption of ${ }^{59} \mathrm{Fe}$ from cooked haemoproteins was very low. 
Table 3. Effect of bovine serum albumin $(B S A)$ on absorption of ${ }^{59} \mathrm{Fe}$-labelled ferritin 120 min after feeding to rats

(Values are means with their standard errors; four rats per group)

\begin{tabular}{|c|c|c|c|}
\hline \multirow[b]{2}{*}{ Test meal (8)* } & \multirow{2}{*}{$\begin{array}{c}\text { Protein } \\
\text { concentration } \\
(\mathrm{mg} / \mathrm{ml})\end{array}$} & \multicolumn{2}{|c|}{$\begin{array}{c}{ }^{59} \mathrm{Fe} \text { absorption } \\
(\%)\end{array}$} \\
\hline & & Mean & $\mathrm{SE}$ \\
\hline $\begin{array}{l}\text { Ferritin } \dagger \\
\text { Ferritin }+ \text { + BSA (mg) }\end{array}$ & $1 \cdot 5$ & $2 \cdot 5$ & 0.1 \\
\hline 200 & $41 \cdot 5$ & $8 \cdot 3$ & 0.4 \\
\hline 400 & 81.5 & $9 \cdot 6$ & 1.3 \\
\hline 1000 & 201.5 & 13.5 & 0.6 \\
\hline
\end{tabular}

* For details of preparation, see p. 513.

$\dagger 5 \mathrm{ml}$ containing $6.7 \mu \mathrm{g} \mathrm{Fe} / \mathrm{ml}$.

\section{Effect of additional protein on ${ }^{59} \mathrm{Fe}$ absorption from ferritin-Fe}

The low ${ }^{59} \mathrm{Fe}$ absorption from ferritin-Fe $(2.5 \%)$ in comparison with that of whole liver $(15.3 \%)$ led us to look at the effect of adding extra protein on ferritin-Fe absorption. Table 3 shows the effect of adding extra bovine serum albumin (BSA) on ${ }^{59} \mathrm{Fe}$ absorption from ferritin. It is clear from the results that BSA has a significant enhancing effect on the absorption of ferritin-Fe, the increase being related to the concentration of added BSA.

\section{DISCUSSION}

Many workers in the field of $\mathrm{Fe}$ absorption consider that meat $\mathrm{Fe}$ is synonymous with haem-Fe but in the present work and that reported elsewhere (Hazell, 1982) it is clear that haem contents of meat from various sources vary quite widely and that in some cases, e.g. chicken, an insoluble form of $\mathrm{Fe}$ (haemosiderin) is the largest component of meat $\mathrm{Fe}$ $(\sim 50 \%)$. The concentrations and distribution of Fe compounds found in the present study for chicken meat are similar to values reported by other workers, although in our study the leg meat myoglobin content was two to three times greater than the haemoglobin content, whereas in the study of Hazell (1982) the haemoglobin content was four to five times greater than the myoglobin content in this type of meat. However, the absolute haemoglobin content found by Hazell (1982) is similar to the level estimated in the present work $(1.9 v .1 .5 \mathrm{mg} / \mathrm{kg}$ respectively). The large discrepancy in myoglobin content is not unexpected since many factors are known to determine muscle myoglobin concentrations, e.g. age, rate of growth, sex, breed and amount of exercise (Lawrie, 1979).

The high Fe content of chicken liver was associated with a high insoluble $\mathrm{Fe}$ content, but ferritin, as expected, was also high $(\sim 25 \%)$ and haem-Fe in relation to total $\mathrm{Fe}$ was quite low $(\sim 15 \%)$.

These findings on the distribution of the Fe compounds in chicken meat and liver are of importance since they cast doubt on the rationale behind the widely held view that radioactively-labelled haemoglobin can always be used as an extrinsic tag for meat $\mathrm{Fe}$ absorption in investigations on $\mathrm{Fe}$ absorption from whole meals in humans. Clearly in some cases haem-Fe is the smallest component of meat $\mathrm{Fe}$ and in these instances an extrinsic tag of haemoglobin may be inappropriate. By comparison of the disappearance of ${ }^{59} \mathrm{Fe}$ at various time intervals from the gastrointestinal tract in rats it was possible to show that the 
percentage Fe absorption from various test meals 120 min after oral dosing was relatively constant and was similar to that measured with a $7 \mathrm{~d}$ faecal collection method. For the raw meat and uncooked extracts 120 min time-periods corresponded with almost complete stomach emptying of the meal but for the other samples up to $30 \%$ of the meal remained in the stomach suggesting that when this meal was released to the duodenum little, if any, further Fe was absorbed. For the uncooked meat and extract high absorption was obtained after $60 \mathrm{~min}$ when the stomach still contained a significant amount of the meal. Thus in $\mathrm{Fe}$-replete rats it would appear that a saturation level of $\mathrm{Fe}$ absorption is reached and once this level is achieved further Fe released from the stomach to the intestinal tract is not absorbed. In the meals rapidly lost from the stomach there appears to be an anomalously-high absorption after 60 min suggesting that at this time-interval $\mathrm{Fe}$ is lost from the system. No explanation for this observation can be given. Using this technique it was possible to show that the various meat $\mathrm{Fe}$ components were absorbed to widely-differing extents in Fe-replete rats (Table 2). Fe-deficient rats, however, continued to absorb a greater percentage of $\mathrm{Fe}$ from chicken leg meat beyond the $2 \mathrm{~h}$ time-interval, an effect which suggests that a saturation level of absorbed $\mathrm{Fe}$ is not achieved and that delayed stomach emptying shown in the present study may aid absorption. The effect may also be related to an increased ability of the ileum to absorb Fe in Fe-deficient, compared with Fe-replete, rats (Turnbull, 1974).

Fe absorption from raw chicken meat (Table 2) was higher than that obtained by Callender (1971) using cooked (casseroled) chicken given to Fe-replete human subjects. One reason may be that the chicken samples in this study were obtained from young broiler chickens ( 8 weeks old) whereas those of Callender (1971) were from much older laying hens (age not reported) and there may well be subtle differences in the nature of the Fe-containing compounds from chickens at different ages. It is more likely, however, to be related to the cooking effect; Fe absorption from cooked chicken being markedly reduced (Table 2) and thus more comparable to that of earlier human studies using cooked chicken. Consideration of Table 2 strongly suggests that the decreased absorption from cooked compared with raw chicken was due to the loss in availability of the haemoproteins following heat treatment. On heat denaturation the haemoproteins in meat coprecipitate with the other proteins present to yield the insoluble cooked meat haemoproteins (Ledward, 1971). These complexes can be solubilized by strong acid to yield acid-haematin and soluble proteins but the present results suggest that the natural acidity of the rat's stomach is not sufficient to bring about this change. Thus throughout the digestion period the haem-Fe is not readily accessible. Cooked liver displayed a significant increase in Fe absorption following heat treatment and presumably this was because the ferritin and haemosiderin (major components) were modified during heat treatment rendering the Fe more available. Certainly the cooked residue from meat (mainly haemosiderin) appeared to be better absorbed than its raw counterpart (Table 2). The variability in $\mathrm{Fe}$ absorption of various meat components (Table 2) showed that the absorption of Fe in the raw soluble extract $(13.4 \%)$ was higher than that in the raw residue $(6.7 \%)$ but neither were as high as in raw whole meat $(18.3 \%)$. The implication is that both components together had a supplementary effect on each other. This effect may be related to the enhancing effect of supplementary protein on the formation of low-molecular-weight non-haem-proteins from haemoglobin which occurs with in vitro systems, the resulting Fe compounds being well absorbed (Hazell et al. 1980). The absorption-enhancing effect of protein was also shown with ferritin, greater quantities of protein improving $\mathrm{Fe}$ absorption dramatically (Table 3). Thus, in evaluating the $\mathrm{Fe}$ availability from even a single food such as chicken meat or liver, one not only has to take account of the concentration and type of each Fe-containing compound present but also their possible synergistic effects, the presence of chelating agents, the extent of cooking and the concentration of enhancing agents such as protein digestion products. 
The authors thank Mr C. Freeman for technical assistance and the Agricultural Research

Council and the Association of Commonwealth Universities for financial support.

\section{REFERENCES}

Bjorn-Rasmussen, E., Hallberg, L., Isaksson, B. \& Ardvidsson, B. (1974). Journal of Clinical Investigation 53, 247-255.

Callender, S. T. (1971). Gerontologia Clinica 13, 44-51.

Conrad, M. E., Benjamin, B. J., Williams, H. L. \& Foy, A. L. (1967). Gastroenterology 53, 5-10.

Hazell, T. (1982). Journal of the Science of Food and Agriculure 33, 1049-1056.

Hazell, T., Ledward, D. A. \& Neale, R. J. (1978). British Journal of Nutrition 39, 631-638.

Hazell, T., Ledward, D. A., Neale, R. J. \& Root, I. C. (1980). Meat Science 5, 397-405.

Lawrie, R. A. (1979). Meat Science, 3rd ed, p. 30. Oxford: Pergamon Press.

Ledward, D. A. (1971). Journal of Food Science 36, 883-888.

Turnbull, A. (1974). In Iron in Biochemistry and Medicine, pp. 370-395 [A. Jacobs and M. Worwood, editors]. London and New York: Academic Press. 